\title{
MICROCRYSTALLINE CELLULOSE FROM GROUNDNUT SHELL AS POTENTIAL ADSORBENT OF CRYSTAL VIOLET AND METHYLENE BLUE. KINETICS, ISOTHERMS AND THERMODYNAMICS STUDIES
}

\author{
Zakariyya Uba Zango 1, 2, , Saifullahi Shehu Imam3, 4
}

https://doi.org/10.23939/chcht14.04.563

\begin{abstract}
The isolation of microcrystalline cellulose from a groundnut shell is reported. Adsorption experiments were carried out for the removal of cationic crystal violet and methylene blue and it follows Langmuir model. Positive enthalpy and negative free energy changes have shown endothermic and favorable processes. The results reflect good adsorption process.
\end{abstract}

Keywords: adsorbent, crystal violet, methylene blue, microcrystalline cellulose.

\section{Introduction}

Water as the source of life, is essential to every aspect of human life. However, at present, the world of ours is facing a challenge of water scarcity due to the rapid growth of population, development of industries, climate change, mismanagement of water use, etc. Currently, around 700 million peoples are suffering from water scarcity in 43 countries and more than two million children under the age of five die every year by waterrelated disease [1].

Considerable amount of wastewater is being generated from different industries including textile, leather, paper, printing, dyestuff, plastic and so on [2]. Large quantities of dangerous dyes, pigments and metals originate from the manufacturing, textile as well as pulp and paper industries are emitted into the water bodies. Removal of such pollutants is very important because water quality is greatly influenced by their presence [3], dyes even in small amount are highly visible and

\footnotetext{
${ }^{1}$ Department of Fundamental and Applied Sciences,

Universiti Teknologi PETRONAS, 32610, Seri Iskandar, Perak, Malaysia

${ }^{2}$ Department of Chemistry, Al-Qalam University Katsina,

P.M.B 2341, Katsina, Nigeria

${ }^{3}$ School of Chemical Sciences, Universiti Sains Malaysia,

11800, Pulau Penang, Malaysia

${ }^{4}$ Departmentof Pure and Industrial Chemistry,

Bayero University, P.M.B 3011, Kano, Nigeria

zakariyyazango4@gmail.com

(c) Zango Z., Imam S., 2020
}

undesirable. Moreover, many dyes are toxic, and some are even carcinogenic [4]. This makes treating water contamination difficult. The color of the dyes tends to persist even after the conventional removal processes [5].The dye contaminations in water prevent light penetration and therefore, affect photosynthesis. Hazardous contaminants enter water mostly through the direct discharge of industrial effluents and urban activities. The presence of hazardous contaminants in water environment creates severe problems for human and water ecosystem [6].

Methylene blue and crystal violet are among the toxic dyes used in textile, paper and cosmetic industries. Methylene blue commonly used in hemp, silk fabric, stained paper dyeing and bamboo, wood coloring, as a chemical agent in printing and dyeing enterprises [7]. It is one of the major contaminants present in wastewater.

Various treatment techniques have been applied for removal of wastewaters containing dyes and heavy metals. Among them include: coagulation, flocculation, adsorption, membrane separation, oxidation, biological, and electrochemical methods [8, 9]. Among various methods employed, adsorption is considered one of the most efficient methods adopted for removing toxic organic dyes from their aqueous solutions [10]. It is a highly convenient and environmentally friendly without the formation of any harmful by-products. Therefore, seeking for renewable, efficient and low-cost adsorbents materials is still in progress. The economic feasibility and environmental importance of both synthetic and natural bio adsorbents are attracting much interest $[11,12]$.

Several low-cost adsorbents ranging from agricultural, domestic or plant biomass waste have been used for the removal of dyes such as grapefruit peel [13], banana peel [14], rice husk [15], jackfruit leaf powder [16], ginger waste [17], etc.

Cellulose is a renewable, biodegradable and nontoxic material. It is also a vast source for environmentally friendly and biocompatible products [18]. The major sources of cellulose are wood and cotton. These materials have been used for centuries as a source of heat 
or as a construction material, or for manufacturing of several commodities in textile and paper industry. Nowadays, cellulose can be derived from a variety of sources, such as woods, annual plants, microbes, and animals. These include seed fiber (cotton), wood fibers (hardwoods and softwood), bast fibres (flax, hemp, jute, ramie), grasses (bagasse, bamboo), algae (Valonia ventricosa), and bacteria (Acetobacter xylinum) $[19,20]$. In nature, the cellulose molecular chains are biosynthesized and self-assembled into microfibers, which are composed of crystalline and amorphous domains. It is one of the major components in lignocellulose materials. This natural polymer has been investigated as a biosorbent in its natural or chemically modified form. In a natural form, it exists in agricultural wastes such as banana peel, saw dust, corncob, and bagasse [21, 22]. Modified cellulose can be divided into two groups, which are direct modification and monomer grafting. The main routes of direct cellulose modification in the preparation of adsorbent materials are esterification, etherification, halogenation, oxidation, alkaline treatment, and silylation [20, 23]. Nanobiomaterials derived from abundant and renewable natural resources could have the potential to replace synthetic nanomaterials [24].

Nano cellulosic materials have many interesting features such as nano dimension (higher surface area to volume ratio), nontoxicity, biodegradability, biocompatibility, etc. Interesting properties of nanocellulose could find applications in the biomedical field, reinforcement in the polymer matrix in order to fabricate nanocomposites, production of renewable energy, environmental remediation, etc. [25]. It is fine, white, odorless, crystalline powder and biodegradable material that can be isolated from $\alpha$-cellulose. The isolation of microcrystalline cellulose particles can be done via mechanical treatments [26], biological treatments [27] and chemical treatments, for instance acid hydrolysis [28, 29].

In this work, microcrystalline cellulose (MCC) was prepared from the groundnut shell as previously reported and its adsorption study towards the removal of two cationic dyes, crystal violet $(\mathrm{CV})$ and methylene blue (MB) were investigated. Kinetic, isotherm and thermodynamic parameters were evaluated for the adsorption process and mechanism.

\section{Experimental}

\subsection{Reagents}

Groundnut shell was collected from Dawanau Market, one of the largest cereals market in Kano Nigeria. Crystal violet $\left(\mathrm{C}_{25} \mathrm{~N}_{3} \mathrm{H}_{30} \mathrm{Cl}\right.$, MW $407.979 \mathrm{~g} / \mathrm{mol})$ and methylene blue $\left(\mathrm{C}_{16} \mathrm{C}_{16} \mathrm{H}_{18} \mathrm{CIN}_{3} \mathrm{~S}\right.$,
MW $319.85 \mathrm{~g} / \mathrm{mol}$ ) were received from Sigma-Aldrich (USA). All chemicals used in this work were of high purity and of analytical reagent (AR) grade and were used as received. Double distilled water (DDW) was used throughout the study.

\subsection{Pulping and Bleaching}

The groundnut shell was grinded and dried in the dark for a period of one week. It was then sieved to obtain finely grinded powder. A cartridge containing $50 \mathrm{~g}$ of dried groundnut shell was placed in a Soxhlet equipped with $1000 \mathrm{ml}$ round bottom flask. The sample was first subjected to extraction at $358 \mathrm{~K}$ with $600 \mathrm{ml}$ of ethanol/toluene $(2 / 1(\mathrm{v} / \mathrm{v}))$ mixture during $24 \mathrm{~h}$. The pulping process was performed under atmospheric pressure. The dried Alfa stems were kept for $4 \mathrm{~h}$ at $358 \mathrm{~K}$ in a $500 \mathrm{ml}$ round bottom flask containing $300 \mathrm{~m}$ of $\mathrm{NaOH}(1 \mathrm{~mol} / \mathrm{l})$, equipped with a reflux condenser and a magnetic stirrer. The obtained mixture was filtered immediately. The residue was successively washed with $350 \mathrm{ml}$ of $\mathrm{NaClO}$ solution $(40 \mathrm{wt} \%)$ for $18 \mathrm{~h}$ at $303 \mathrm{~K}$, $250 \mathrm{ml}$ of ethanol for $2 \mathrm{~h}$ at $303 \mathrm{~K}$ and $250 \mathrm{ml}$ of diethyl ether for $2 \mathrm{~h}$ at ordinary temperature [30]. After this treatment, the cellulose pulp was washed with distilled water until $\mathrm{pH}$ of 7 was reached. At last, the residue obtained was dried for $24 \mathrm{~h}$ at $333 \mathrm{~K}$.

\subsection{Preparation of Microcrystalline Cellulose}

Microcrystalline cellulose was isolated from the pulp using a method described in [31]. $100 \mathrm{ml}$ of $2.5 \mathrm{~N}$ $\mathrm{HCl}$ solution was taken in a $250 \mathrm{ml}$ flask and kept in a heating mantel. The temperature of heating mantel was kept constant at $358 \mathrm{~K}$ and stirring of $\mathrm{HCl}$ solution started. After getting $358 \mathrm{~K}$ temperature of $\mathrm{HCl}$ solution, $100 \mathrm{~g}$ of the groundnut shell pulp were added in the solution slowly with a continuous stirring. After complete addition of the powder, the mixture was kept under continuous stirring for one and a half hour. After complete depolymerization of the powder, the heating and stirring were stopped and the mixture was kept for cooling.

The mixture was then neutralized with water to get the neutral $\mathrm{pH}$ of the wash water. Then it was filtered with the Whatman 42 filter paper to separate the microcrystalline cellulose (MCC) and water. The obtained microcrystalline cellulose was washed with acetone to remove traces of water present. It was filtrated to separate acetone and microcrystalline cellulose. Lastly, the microcrystalline cellulose was kept for natural drying. After complete drying, the obtained microcrystalline cellulose was weighted. 


\subsection{Preparation of Adsorbate}

The adsorbates, crystal violet $(\mathrm{CV})$ and methylene blue (MB) dye solutions were prepared by measuring $100 \mathrm{mg}$ of each dyes followed by dissolving in $20 \mathrm{ml}$ of distilled water. The solution was transferred into a $1000 \mathrm{ml}$ volumetric flask and distilled water was added to the mark. The concentrations of the resulting solutions were $100 \mathrm{mg} / \mathrm{l}$. The solutions of different concentrations used in various experiments were obtained by dilution of the stock solutions. The stock solution was prepared every day. All solutions were prepared with distilled water.

\subsection{Effect of Initial Dye Concentrations}

Batch adsorption experiments were conducted to determine the equilibrium adsorption capacity and the removal efficiency of the dyes. The concentration of the dyes varied (50, 100, 150 and $200 \mathrm{mg} / \mathrm{l})$. Experiments were conducted in Erlenmeyer flask filled with dyes of various concentrations $(50 \mathrm{ml})$ and adsorbent dose of $0.1 \mathrm{~g}$, placed on a shaker $(300 \mathrm{rpm})$ at room temperature. Adsorption process was monitored by using a UV-Vis spectrophotometer (Varian CARY 50 probe). At predetermined time intervals, aliquots were withdrawn, and their absorbencies were measured at 590 and $670 \mathrm{~nm}$ for $\mathrm{CV}$ and $\mathrm{MB}$, respectively, for the determination of the residual dye concentrations.

The optimum time is obtained from the plot adsorption capacity versus time using Eq. (1):

$$
q_{t}=\frac{\left(C_{0}-C_{t}\right) \cdot V}{w}
$$

Also, the equilibrium time for the adsorption of the dye is obtained using Eq. (2):

$$
q_{e}=\frac{\left(C_{0}-C_{e}\right) \cdot V}{w}
$$

The percentage removal $(\% R)$ is calculated from the formula:

$$
\% R=\frac{C_{0}-C_{e}}{C_{0}} \cdot 100
$$

where $C_{0}, C_{t}$ and $C_{e}$ are initial, time and equilibrium concentrations of the dye, respectively, $\mathrm{mg} / \mathrm{l} ; w$ is the weight of the adsorbent, $\mathrm{g}$; $V$ is the volume of dye solution, 1 .

\subsection{Adsorption Kinetics Study}

Determination of rate constant is among the most important factors evaluated in adsorption studies. In wastewater treatment an adsorbent must have not only the high adsorption capacity but also a fast adsorption rate. Kinetic models have been proposed to understand the mechanism and to scale-up the efficiency of the adsorption process. In order to investigate the potential rate determining step, 3 models were employed in this work: pseudo-first order, pseudo-second order, intraparticle diffusion models. They were tested on the experimental data.

\subsubsection{The pseudo-first order kinetic model}

This kinetic model was proposed by Lagergren [32] to predict the dye adsorption kinetics. It is expressed linearly as:

$$
\log \left(q_{e}-q_{t}\right)=\log q_{e}-\frac{k_{1}}{2.303} t
$$

where $q_{e}$ and $q_{t}$ are the amounts of dye adsorbed at equilibrium and time $t$, respectively, $\mathrm{mg} / \mathrm{g} ; k_{1}(1 / \mathrm{min})$ is the equilibrium rate constant of the pseudo-first order. The kinetics parameters are obtained from the plot $\log \left(q_{e}-q_{t}\right)$ vs.t.

\subsubsection{The pseudo-second order kinetic model}

This kinetic model was used by Ho to analyze the adsorption kinetic data [33]. It is expressed as:

$$
\frac{t}{q_{t}}=\frac{1}{k_{2} q_{e}^{2}}+\frac{t}{q_{e}}
$$

where $k_{2}$ is the equilibrium rate constant of the pseudosecond order, $\mathrm{g} / \mathrm{mg} \cdot \mathrm{min}$. In this case, the kinetics parameters can be calculated from the plot $t / q_{t} v s . t$.

\subsection{Adsorption Isotherms}

Adsorption isotherms are used to explain the interaction between the adsorbate and adsorbent in adsorption study. It indicates how the adsorbate molecules interact with adsorbent and attain equilibrium. It also explains how the adsorption molecules distribute between the liquid phase and the solid phase when the adsorption process reaches an equilibrium state. For the sake of this study, 3 adsorption isotherms models were employed. They are Langmuir, Freundlich and Temkin isotherm models.

\subsubsection{Langmuir isotherm}

The Langmuir model assumes a monolayer sorption on a surface with a finite number of identical sites [34]. The model is based on the following assumptions: (i) the forces of interaction between the adsorbed molecules are negligible; (ii) no further adsorption occurs when the adsorption site is occupied; (iii) adsorption occurs at a specific homogeneous adsorption sites within the adsorbent; (iv) the intermolecular forces of attraction will weaken rapidly with distance [35].

The linear form of the Langmuir isotherm model is given by Eq. (6): 


$$
\frac{C_{e}}{q_{e}}=\frac{1}{Q_{0} b}+\frac{C_{e}}{Q_{0}}
$$

where $C_{e}$ is the equilibrium concentration of the dye, $\mathrm{mg} / \mathrm{l} ; q_{e}$ is the amount of adsorbate adsorbed per unit mass of adsorbent, $\mathrm{mg} / \mathrm{g} ; Q_{0}$ and $b$ are the Langmuir constants related to the adsorption capacity and rate of adsorption, respectively. The plot of $C_{e} / q_{e} v s . C_{e}$ gives a straight line with the slope of $1 / Q_{0}$.

\subsubsection{Freundlich isotherm}

The Freundlich isotherm is an empirical equation that can be satisfactorily used to identify a non-ideal adsorption of heterogeneous surface energy systems. The linear form of the Freundlich isotherm model is defined by the following equation [36].

$$
\ln q_{e}=\frac{1}{n} \ln C_{e}+\ln K_{F}
$$

where $q_{e}$ is the amount of solute adsorbed per unit weight of adsorbent, $\mathrm{mg} / \mathrm{g} ; C_{e}$ is the equilibrium concentration of the solute in the bulk, mg/l; $K_{F}$ is a Freundlich constant indicating the relative adsorption capacity of the adsorbent, $\mathrm{mg} / \mathrm{g} ; 1 / n$ is the adsorption intensity. The Freundlich parameters $K_{F}$ and $n$ are obtained from the plot of $\ln q_{e} v s . \ln C_{e}$.

\subsubsection{Temkin isotherm}

Temkin isotherm model takes into account the effect of indirect interaction between adsorbate and assumes that the heat of adsorption of all the molecules in the layer would decrease linearly with the coverage due to the interactions. The Temkin isotherm is given as:

$$
q_{e}=\frac{R T}{b_{T}} \ln K_{T}+\frac{R T}{b_{T}} \ln C_{e}
$$

where $b_{T}$ is the Temkin constant related to the heat of adsorption, $\mathrm{kJ} \cdot \mathrm{mol}^{-1} ; K_{T}$ is the equilibrium binding constant corresponding to the maximum binding energy, $1 \cdot \mathrm{g}^{-1} ; T$ is the absolute temperature, $\mathrm{K} ; R$ is the gas constant $\left(8.314 \mathrm{~J} \mathrm{~K}^{-1} \mathrm{~mol}\right)$. The Temkin constants, $b_{T}$ and $K_{T}$ were obtained from the plot of $q_{e} v s . \ln C_{e}$.

\subsection{Effect of Temperature}

The effect of temperature for the removal of $\mathrm{CV}$ and $\mathrm{MB}$ has been studied. Adsorption studies for the removal of $\mathrm{CV}$ and $\mathrm{MB}$ were conducted at different temperatures of $293,303,313,323$ and $333 \mathrm{~K}$ with a constant initial concentration of $50 \mathrm{mg} / 1$ at a stirring speed of $300 \mathrm{rpm}$.

\subsection{Thermodynamic Studies}

Thermodynamic considerations of an adsorption process are necessary to conclude whether the process is spontaneous or not. It can be explained thermodynamically by evaluating parameters such as the change in free energy $\left(\Delta G^{0}\right)$, enthalpy $\left(\Delta H^{0}\right)$ and entropy $\left(\Delta S^{0}\right)$ [37]. The experimental data obtained at different temperatures were used in calculating the thermodynamic parameters.

The Gibbs free energy change of the sorption reaction is given by the following equations [38]:

$$
\begin{gathered}
\Delta G^{0}=-R T \ln K_{L} \\
\Delta G^{0}=\Delta H^{0}-T \Delta \mathrm{S}^{0}
\end{gathered}
$$

where $K_{L}$ is the equilibrium constant, which is obtained from Langmuir isotherms; $R$ is the universal gas constant, $8.314 \mathrm{~J} \cdot \mathrm{mol}^{-1} \cdot \mathrm{K}^{-1}$, and $T$ is absolute temperature, $\mathrm{K} . \Delta H^{0}$ and $\Delta S^{0}$ were obtained from the slope and intercept of the plot of $\Delta G^{0} v s . T$.

\section{Results and Discussion}

\subsection{Effect of Initial Dye Concentration}

The removal of crystal violet (CV) and methylene blue (MB) concentrations are depicted in Fig. 1. The percentages removals reduced with changing the initial concentrations of both dyes. When $50 \mathrm{mg} / \mathrm{l}$ of the dyes were used, almost complete removals of both dyes were observed within 240 and $220 \mathrm{~min}$ for $\mathrm{CV}$ and $\mathrm{MB}$, respectively. However, with higher dye concentrations of $200 \mathrm{mg} / \mathrm{l}, 68 \%$ and $52 \%$ removals were recorded, respectively, with constant time intervals. The observed trend at lower dye concentrations is attributed to the ratio of the number of dye molecules with the availability in adsorption sites on the adsorbent [38]. However, with increasing concentrations, the available active sites in the adsorbent became readily occupied by the dye molecules, thus the subsequent decrease in the removal capacities at higher concentrations were observed [39]. The equilibrium adsorption capacities are much higher when the initial concentration of the dye was increased. Similar regularities were found in $[40,41]$.

\subsection{Adsorption Kinetics}

The values of $q_{e}, k_{1}$ and $R^{2}$ obtained from the plot of pseudo-first order (Fig. 2), as well as $q_{e}, k_{2}$ and $R^{2}$ obtained from the plot of the pseudo-second order (Fig. 3) for the $\mathrm{CV}$ and $\mathrm{MB}$ adsorption on to groundnut MCC are reported in Table 1. The $R^{2}$ values obtained for the second-order kinetics model at different initial dye concentrations were relatively high $\left(R^{2}>0.99\right)$, and the equilibrium adsorption capacity values calculated $\left(q_{e, c a l}\right)$ by the same model for both $\mathrm{CV}$ and $\mathrm{MB}$ are very close to the experimental equilibrium adsorption capacity $\left(q_{e, e x p}\right)$. Compared to the pseudo-second order, the pseudo-first order model did not 
show a consistent trend and also the experimental $q_{e}$ values were not in agreement with the calculated values obtained from the graphs. This indicated that adsorption of $\mathrm{CV}$ and MB onto groundnut MCC did not follow the pseudo firstorder kinetic model. The data fitted the pseudo-second

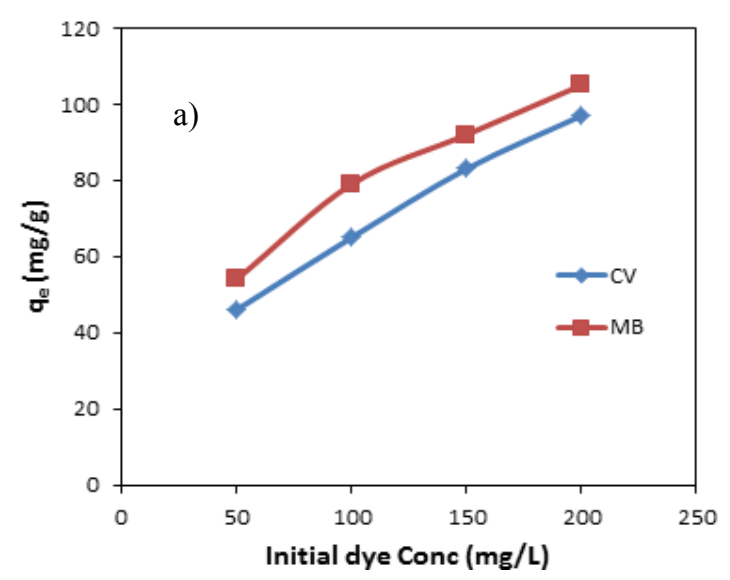

order kinetics model better. Generally, for the pseudosecond order model, the rate-limiting step is the surface adsorption that involves chemisorption, where the removal from a solution was due to physicochemical interaction between two phases [42].

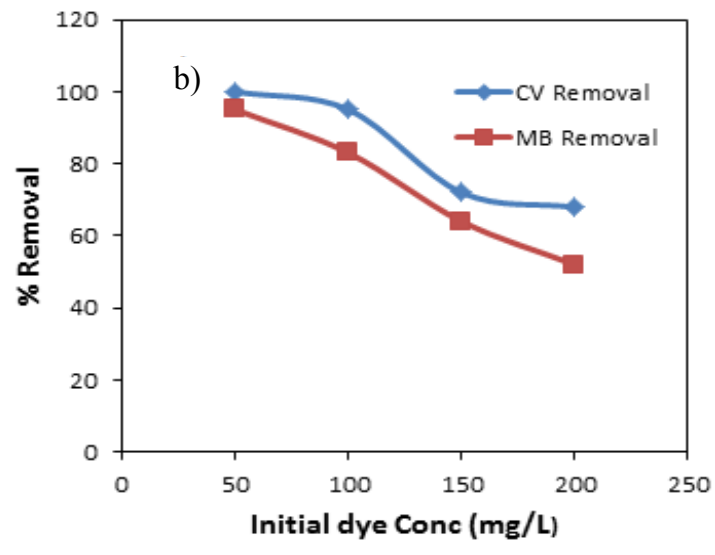

Fig. 1. Amounts (a) and percentage removals of $\mathrm{CV}$ and $\mathrm{MB} v s$. initial dye concentrations
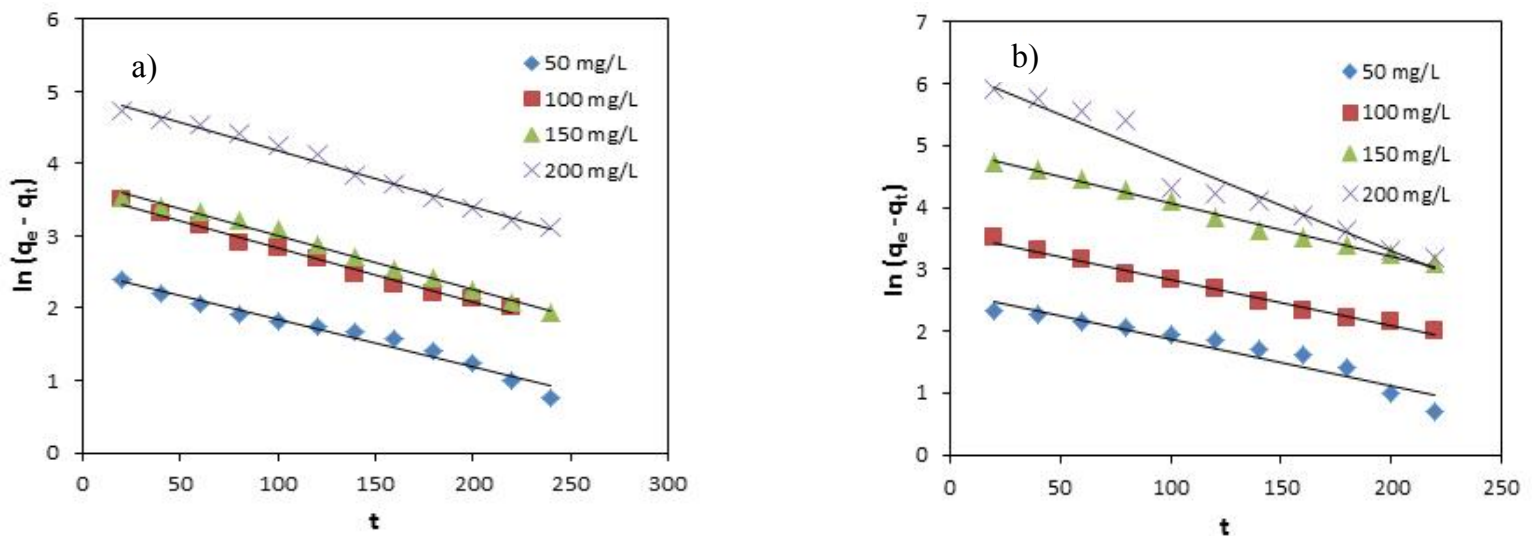

Fig. 2. The pseudo first-order kinetic model for the adsorption of CV (a) and MB (b) onto the MCC

Table 1

Kinetic model parameters for the adsorption of CV and MB onto groundnut shell MCC

\begin{tabular}{|c|c|c|c|c|c|c|c|}
\hline \multirow{3}{*}{ Dye concentrations, $\mathrm{mg} / \mathrm{L}$} & \multicolumn{7}{|c|}{ Kinetic models } \\
\hline & \multicolumn{4}{|c|}{ Pseudo-first order } & \multicolumn{3}{|c|}{$\begin{array}{l}\text { Pseudo-second order } \\
\end{array}$} \\
\hline & $q_{e, \exp }, \mathbf{m g} / \mathbf{g}$ & $q_{e, c a l}, \mathbf{m g} / \mathbf{g}$ & $k_{1}, \min ^{-1}$ & $\boldsymbol{R}^{2}$ & $q_{e, c a l}, \mathbf{m g} / \mathbf{g}$ & $k_{2}, \min ^{-1}$ & $\boldsymbol{R}^{2}$ \\
\hline \multicolumn{8}{|c|}{$\mathrm{CV}$} \\
\hline 50 & 46 & 42 & 0.015 & 0.969 & 44 & 0.012 & 0.993 \\
\hline 100 & 65 & 54 & 0.012 & 0.922 & 67 & 0.014 & 0.989 \\
\hline 150 & 83 & 67 & 0.013 & 0.993 & 88 & 0.012 & 0999 \\
\hline 200 & 97 & 74 & 9.018 & 0.990 & 95 & 0.017 & 0.997 \\
\hline \multicolumn{8}{|c|}{ MB } \\
\hline 50 & 54 & 47 & 0.017 & 0.922 & 56 & 0.014 & 0.999 \\
\hline 100 & 79 & 63 & 0.017 & 0.990 & 74 & 0.013 & 0.985 \\
\hline 150 & 92 & 75 & 0.019 & 0.991 & 96 & 0.018 & 0.997 \\
\hline 200 & 105 & 97 & 0.034 & 0.993 & 107 & 0.012 & 0.991 \\
\hline
\end{tabular}



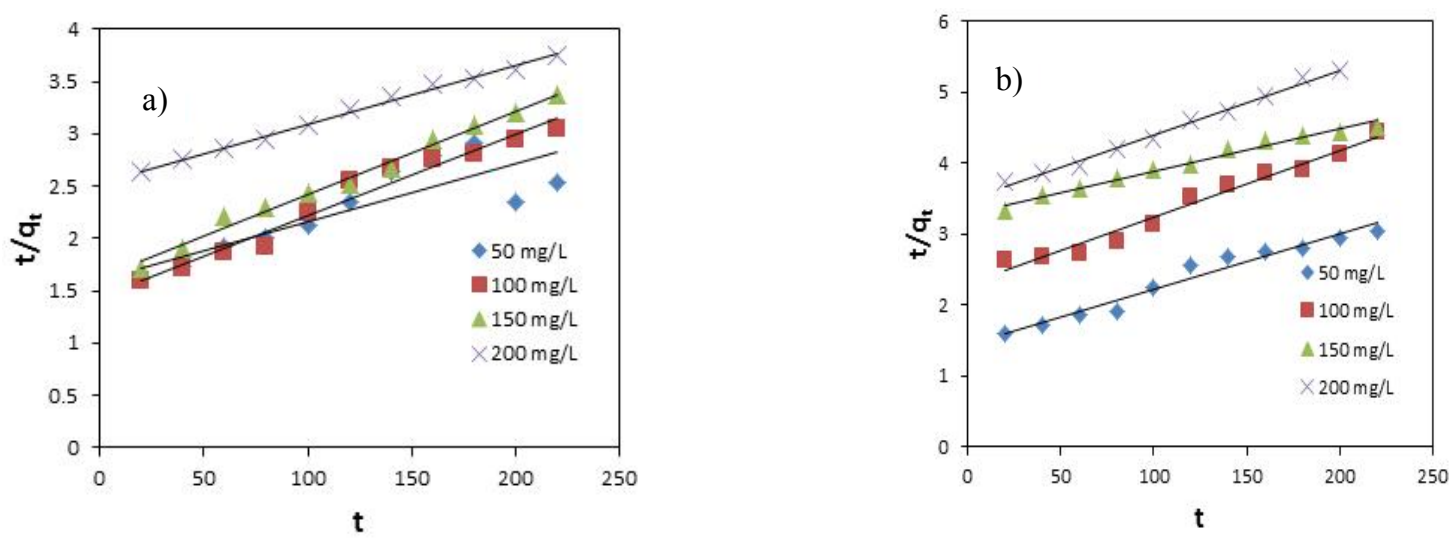

Fig. 3. The pseudo second-order kinetic for the adsorption of CV (a) and MB (b) onto the MCC

\subsection{Isotherm Models}

Values of the isotherm parameters are shown in Table 2. It is observed that Langmuir isotherm (Fig. 4a) has given higher values of 0.999 and 0.972 for $\mathrm{CV}$ and $\mathrm{MB}$, respectively, compared to Freundlich and Temkin isotherms (Figs. 4b and 4c) with higher adsorption capacity $\left(Q_{a}^{0}\right)$ of $58.82 \mathrm{mg} / \mathrm{g}$ and $45.66 \mathrm{mg} / \mathrm{g}$ for monolayer due to $\mathrm{CV}$ and $\mathrm{MB}$, respectively. The results show that both dye molecules are on the monolayer which is specifically homogeneous. Also the dye molecules
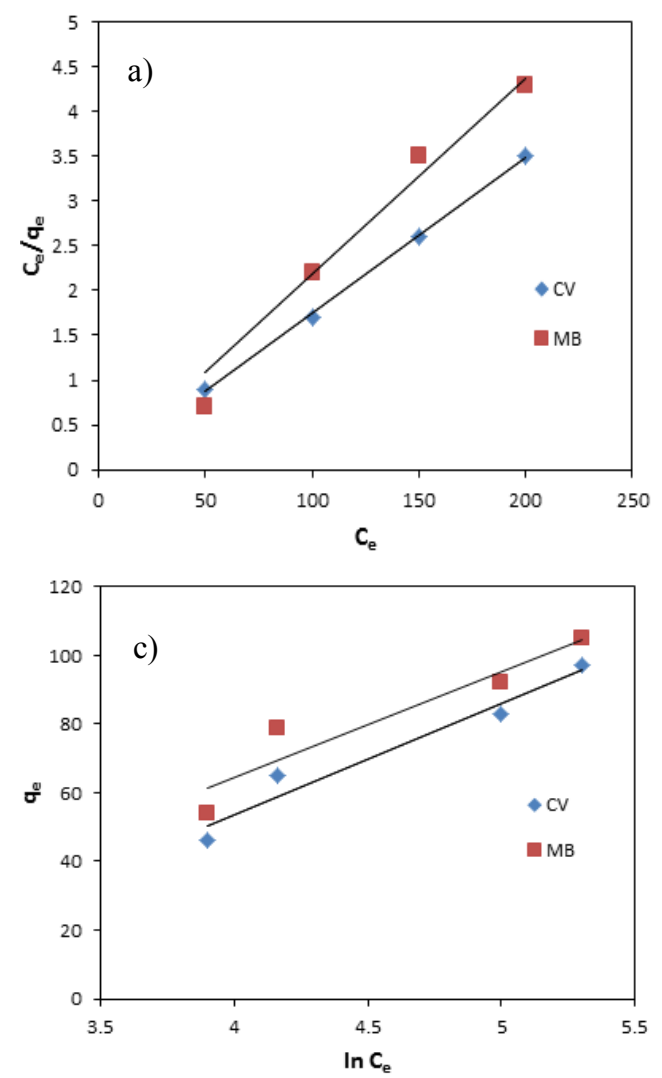

which are adsorbed on the active site have direct interaction with the neighboring molecules of the remaining active sites and the active sites possess equivalent energy. The adsorption capacity values due to monolayer coverage on the groundnut shell MCC has almost similar range with commercial activated carbon materials (for Norit SA3 $Q_{a}^{0}=91 \mathrm{mg} / \mathrm{g}$ and for Nuchar WWH $Q^{0}{ }_{a}=21.50 \mathrm{mg} / \mathrm{g}$ ) [43], thus justification could be made on its uses as a good natural material for dyes adsorptions. Similar observations were reported elsewhere [44].

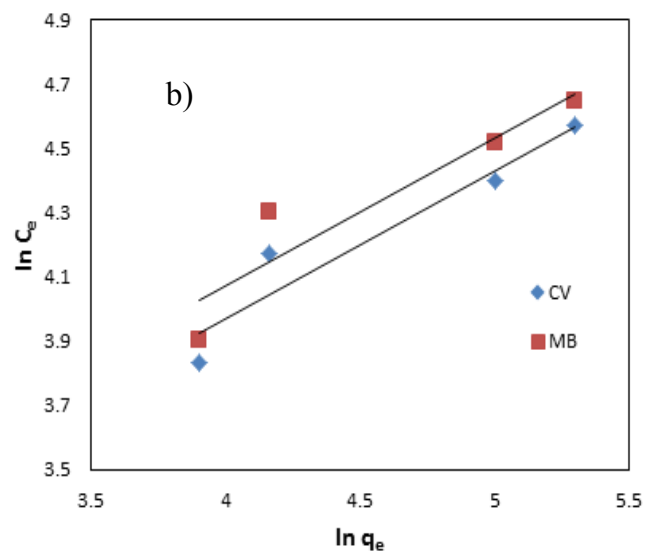

Fig. 4. Isotherm models for the removal of $\mathrm{CV}$ and $\mathrm{MB}$ by the MCC: Langmuir (a), Freundlich (b) Temkin (c) 
Isotherm parameters for the adsorption of crystal violet by the MCC

\begin{tabular}{|c|c|c|c|c|c|c|c|c|c|}
\hline \multirow{3}{*}{ Dye } & \multicolumn{9}{|c|}{ Isotherms } \\
\cline { 2 - 10 } & \multicolumn{3}{|c|}{ Langmuir } & \multicolumn{3}{c|}{ Freundlich } & \multicolumn{3}{c|}{ Temkin } \\
\cline { 2 - 10 } & $\boldsymbol{Q}_{\mathbf{0}}, \mathbf{m g} / \mathbf{g}$ & $\boldsymbol{K}_{\boldsymbol{L}}, \mathbf{L} / \mathbf{m g}$ & $\boldsymbol{R}^{2}$ & $\boldsymbol{K}_{\boldsymbol{F}}, \mathbf{m g} / \mathbf{g}$ & $\boldsymbol{n}$ & $\boldsymbol{R}^{2}$ & $\boldsymbol{b}_{\boldsymbol{T}}, \mathbf{k J} / \mathbf{m o l}$ & $\boldsymbol{K}_{\boldsymbol{T}}, \mathbf{L} / \mathbf{g}$ & $\boldsymbol{R}^{\mathbf{2}}$ \\
\hline $\mathbf{C V}$ & 58.82 & 1.107 & 0.999 & 8.435 & 2.175 & 0.916 & 9.451 & 0.302 & 0.953 \\
MB & 45.66 & 1.112 & 0.972 & 9.264 & 2.168 & 0.876 & 12.912 & 0.203 & 0.889 \\
\hline
\end{tabular}

\subsection{Effect of Temperature}

Investigation of the adsorption temperature effect is paramount in view of its practicability. The temperature and the removal efficiency relationship for the adsorption of $\mathrm{CV}$ and MB by the groundnut MCC are shown in Fig. 5. The percentage removals of both dyes increase with increasing the temperature from 303 to $343 \mathrm{~K}$. For CV the percentage removal was found to be increased from 85 to $100 \%$ when the temperature was increased. Also, for the MB dye, the percentage removal increased from 95 to $100 \%$. The increase in removal efficiency was related to the increased ion mobility. The adsorption takes place due to surface activities of the solute and the kinetic energy. Also, the adsorptions were found to be endothermic internal structure of absorbent swelling, thereby allowing penetrating the large molecule of the dyes. The similar observations using a coconut shell activated carbon for dyes removal were reported in [45].

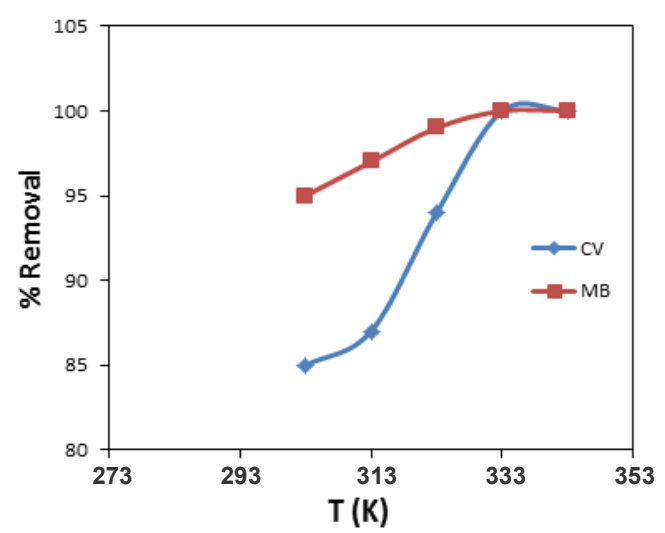

Fig. 5. Effect of temperature for the adsorption of $\mathrm{CV}$ and $\mathrm{MB}$ by the groundnut shell MCC

\subsection{Thermodynamic Analysis}

The parameters of thermodynamic studies $\left(\Delta H^{0}\right.$, $\Delta S^{0}$ and $\Delta G^{0}$ ) for the adsorptions of both dyes are listed in Table 3. Positive $\Delta H^{0}$ values were found for $\mathrm{CV}$ and MB (22.84 and $36.35 \mathrm{~kJ} \mathrm{~mol}^{-1}$, respectively). This indicates that the adsorption process for the dyes removal by the groundnut $\mathrm{MCC}$ is endothermic in nature (Fig. 6). The calculated $\Delta G^{0}$ values also predict the favorability and spontaneity of the adsorptions and decrease with the increase in temperature. The entropy changes, $\Delta S^{0}$, were found to be the positive values for $\mathrm{CV}$ and $\mathrm{MB}$ (32 and $35 \mathrm{~J} \cdot \mathrm{K}^{-1}$, respectively), which indicate the randomness adsorptions that prevail in the whole system. The results have reflected on the affinity of the MCC material adsorbent for the removal of dye molecules [46].

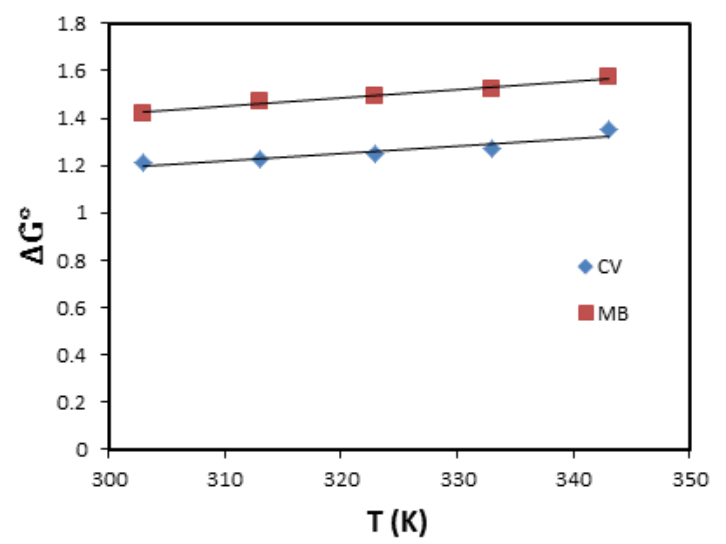

Fig. 6. Thermodynamics for the adsorption of $\mathrm{CV}$ and $\mathrm{MB}$ by groundnut shell MCC

Thermodynamic values for the removal of CV and MB by the MCC

\begin{tabular}{|c|c|c|c|c|c|c|c|}
\hline \multicolumn{4}{|c|}{ CV } & \multicolumn{4}{|c|}{ MB } \\
\hline Temperature, $\mathrm{K}$ & $\underset{\mathbf{k J} \cdot \mathbf{m o l}^{-1}}{\Delta G^{0}}$ & $\begin{array}{c}\Delta H^{0} \\
\mathbf{k J} \cdot \mathbf{m o l}^{-1}\end{array}$ & $\Delta S^{0}, \mathbf{J} \cdot \mathbf{K}^{-1}$ & $\begin{array}{c}\text { Temperature, } \\
\text { K }\end{array}$ & $\Delta G^{0}, \underset{1}{\mathrm{~kJ} \cdot \mathrm{mol}^{-}}$ & $\begin{array}{c}\Delta H^{0} \\
\mathbf{k J} \cdot \mathbf{m o l}^{-1}\end{array}$ & $\begin{array}{l}\Delta S^{0} \\
\mathbf{J} \cdot \mathbf{K}^{-1}\end{array}$ \\
\hline 303 & -1.21 & & & 303 & -1.42 & & \\
\hline 313 & -1.23 & 22.84 & 32.00 & 313 & -1.47 & 36.35 & 35.00 \\
\hline 323 & -1.25 & & & 323 & -1.49 & & \\
\hline 333 & -1.27 & & & 333 & -1.52 & & \\
\hline 343 & -1.35 & & & 343 & -1.57 & & \\
\hline
\end{tabular}




\section{Conclusions}

Microcrystalline cellulose (MCC) was isolated from groundnut shell and successfully applied as the adsorbent for cationic dyes (CV and $\mathrm{MB}$ ) removal. Effect of initial dye concentrations shows higher removal of both $\mathrm{CV}$ and $\mathrm{MB}$ when smaller concentrations were used, almost complete removals were achieved within $220 \mathrm{~min}$. However, increasing the concentration to $200 \mathrm{mg} / 1$ has considerably reduced the adsorption capacity for $\mathrm{CV}$ and $\mathrm{MB}$ to 42 and $54 \%$, respectively. Adsorption kinetic studies have shown the pseudo-second order model to be the best for fitting the adsorption mechanism with experimental and calculated equilibrium adsorption capacities very close to each other. Higher $R^{2}$ values of 0.999 and 0.992 obtained from Langmuir adsorption isotherm model for both dyes made it best for the adsorption process. The increase in temperature has resulted in higher removal efficiency which indicated the endothermic nature of the process. Negative $\Delta G^{0}$ values indicate the spontaneous nature of the whole process and the higher entropy values which reflect the higher affinity of the adsorbent to the CV and $\mathrm{MB}$ removals. Based on the results obtained, it could be concluded that the MCC from the groundnut shell could be termed as a suitable material for $\mathrm{CV}$ and $\mathrm{MB}$ removals in wastewater.

\section{Acknowledgements}

The authors wish to thank Department of Chemistry, Al-Qalam University Katsina for providing funds to conduct the research.

\section{References}

[1] Putro J., Kurniawan J., Ismadji S., Ju Y.-H.: Environ.

Nanotechnol. Monit. Manag., 2017, 8, 134.

https://doi.org/10.1016/j.enmm.2017.07.002

[2] Crini G.: Bioresour. Technol., 2006, 97, 1061.

https://doi.org/10.1016/j.biortech.2005.05.001

[3] Ni Z., Xia X., Wang L. et al.: J. Colloid Interface Sci., 2007, 316, 284. https://doi.org/10.1016/j.jcis.2007.07.045

[4] Luo X., Zhang L.: J. Hazard. Mater., 2009, 171, 340.

https://doi.org/10.1016/j.jhazmat.2009.06.009

[5] Visa A., Bogatu M., Duta C.: Appl. Surf. Sci., 2010, 256,

5486. https://doi.org/10.1016/j.apsusc.2009.12.145

[6] Singh K., Mohan D., Sinha S. et al.: Ind. Eng. Chem. Res., 2003, 42, 1965. https://doi.org/10.1021/ie020800d

[7] Ghosh B., Bhattacharyya K.: Appl. Clay Sci., 2002, 20, 295.

https://ac.els-cdn.com/S0169131701000813/1

[8] Ciardelli G., Corsi L., Marcucci M.: Resour. Conserv. Recycl., 2001, 31, 189. https://doi.org/10.1016/S0921-3449(00)00079-3

[9] Mahdavinia G., Bazmizeynabad F., Sayyedi B.: Desalin. Water Treat., 2015, 53, 2529.

https://doi.org/10.1080/19443994.2013.870741
[10] Salama A.: J. Colloid Interface Sci., 2017, 487, 348.

https://doi.org/10.1016/j.jcis.2016.10.034

[11] Sharma P., Kaur H., Sharma M., Sahore V.: Environ. Monit. Assess., 2011, 183, 151. https://doi.org/10.1007/s10661-011-

1914-0

[12] Ipek I., Kabay N., Yuksel M.: J. Water Proc. Eng., 2017, 16, 206. https://doi.org/10.1016/j.jwpe.2017.01.006

[13] Saeed A., Sharif M., Iqbal M.: J. Hazard. Mater., 2010, 179, 564. https://doi/org/10.1016/j.jhazmat.2010.03.041

[14] Dahiru M., Zango Z., Haruna M.: Am. J. Mater. Sci., 2018, 8, 32. https://doi.org/10.5923/j.materials.20180802.02

[15] Chakraborty S., Chowdhury S., Saha D.: Carbohydr. Polym., 2011, 86, 1533. https://doi.org/10.1016/j.carbpol.2011.06.058

[16] Saha P., Chakraborty S., Chowdhury S.: Colloids Surface B, 2012, 92, 262. https://doi.org/10.1016/j.colsurfb.2011.11.057

[17] Kumar R., Ahmad R.: Desalination, 2011, 265, 112. https://doi.org/10.1016/j.desal.2010.07.040

[18] Zango Z., Imam S.: Nanosci. Nanotechnol., 2018, 8, 1. https://doi.org/10.5923/j.nn.20180801.01

[19] Klemm A., Heublein D., Fink H., Bohn B.: Angew. Chemie Int. Ed., 2005, 44, 3358. https://doi.org/10.1002/anie.200460587

[20] Hokkanen M., Bhatnagar S., Sillanpaa A.: Water Res., 2016, 91, 156. https://doi.org/10.1016/j.watres.2016.01.008

[21] Annadurai G., Juang R., Lee D.: J. Hazard. Mater., 2002, B92, 263. https://doi.org/10.1016/S0304-3894(02)00017-1

[22] Ngah W., Hanafiah M.: Bioresour. Technol., 2008, 99, 3935. https://doi.org/10.1016/j.biortech.2007.06.011

[23] O’Connell D., Birkinshaw C., O’Dwyer T.: Bioresour.

Technol., 2008, 99, 6709.

https://doi.org/10.1016/j.biortech.2008.01.036

[24] Deepa B., Abraham E., Cordeiro N. et al.: Cellulose, 2015,

22, 1075. https://doi.org/10.1007/s10570-015-0554-x

[25] Mondal S.: Carbohydr. Polym., 2017, 163, 301.

https://doi.org/10.1016/j.carbpol.2016.12.050

[26] Hanna M., Biby G., Miladinov V.: US Pat. 6,228,213 B1

Publ. May 08, 2001.

[27] Islam M., Kao N., Bhattacharya S. et al.: Chin. J. Chem. Eng, 2018, 26, 465. https://doi.org/10.1016/j.cjche.2017.07.004

[28] Muhammad Haafiz M., Eichhorn S., Hassan A., Jawaid M.: Carbohydr. Polym., 2013, 93, 628.

https://doi.org/10.1016/j.carbpol.2013.01.035

[29] Trache D., Donnot A., Khimeche K. et al.: Carbohydr.

Polym., 2014, 104, 223.

https://doi.org/10.1016/j.carbpol.2014.01.058

[30] Maafi E., Malek F., Tighzert L., Dony P.: J. Polym. Environ., 2010, 18, 638. https://doi.org/10.1007/s10924-010-0218-8

[31] Chuayjuljit S., Su-uthai S., Charuchinda S.: Waste Manag. Res., 2010, 28, 109. https://doi.org/10.1177/0734242X09339324

[32] Lagergren S.: Kungliga Svenska Vetenskapsakademiens. Handlingar, 1898, 24, 1.

[33] Wu R., Tseng F., Huang R., Juang S.: Chem. Eng. J., 2009, 151, 1. https://doi.org/10.1016/j.cej.2009.02.024

[34] Wong Y., Szeto Y., Cheung W., McKay G.: Langmuir, 2003, 19, 7888. https://doi.org/10.1021/la030064y

[35] Naseeruteen F., Hamid N., Suah F. et al.: Int. J. Biol.

Macromol., 2018, 107, 1270.

https://doi.org/10.1016/j.ijbiomac.2017.09.111

[36] Xiong L., Yang Y., Mai M. et al.: Chem. Eng. J., 2010, 156,

313. https://doi.org/10.1016/j.cej.2009.10.023

[37] Aydın Y., Aksoy N.: Chem. Eng. J, 2009, 151, 188.

https://doi.org/10.1016/j.cej.2009.02.010

[38] Gharieb M., Al-Fakih A., Ali M.: Arab. J. Sci. Eng., 2014,

39, 2435. https://doi.org/10.1007/s13369-013-0784-x 
[39] Batmaz R., Mohammed N., Zaman M. et al.: Cellulose, 2014, 21, 1655. https://doi.org/10.1007/s10570-014-0168-8

[40] Zango Z., Garba Z., Abu Bakar N. et al.: Appl. Clay Sci., 2016, 132-133, 68. https://doi.org/10.1016/j.clay.2016.05.016 [41] Habiba U., Joo T., Siddique T. et al.: Int. J. Biol. Macromol., 2017, 104, 1133. https://doi.org/10.1016/j.ijbiomac.2017.07.007 [42] Hongxing H., Qiang G., Changgen F.: RSC Adv., 2017, 7, 15102. https://doi.org/10.1039/C7RA00101K

[43] Zhang Z., Wang W., Wang A.: J. Environ. Sci., 2015, 33, 106. https://doi.org/10.1016/j.jes.2014.12.014

[44] Hussin M., Pohan N., Garba Z. et al.: Int. J. Biol. Macromol., 2016, 92, 11. https://doi.org/10.1016/j.ijbiomac.2016.06.094

[45] Kumar K., Ramamurthi V., Sivanesan S.: J. Colloid Interface, 2005, 284, 14. https://doi.org/10.1016/j.jcis.2004.09.063

[46] Kulkarni M., Revanth T., Acharya A., Bhat P.: Resour.

Technol., 2017, 3, 71. https://doi.org/10.1016/j.reffit.2017.01.009

Received: January 09, 2019 / Revised: March 02, 2019 / Accepted: June 20, 2019
МІКРОКРИСТАЛІЧНА ЦЕЛЮЛОЗА 3 АРАХІСОВОЇ ШКАРАЛУПИ ЯК ПОТЕНЦІАЛЬНИЙ АДСОРБЕНТ КРИСТАЛІЧНОГО ФІОЛЕТОВОГО І МЕТИЛЕНОВОГО СИНЬОГО. КІНЕТИЧНІ, IЗОТЕРМІЧНI ТА ТЕРМОДИНАМІЧНІ ДОСЛІДЖЕННЯ

Анотація. Мікрокристалічну целюлозу одержано з арахісової икаралупи. Проведено адсорбцію для видалення катіонних барвників: кристалічного фіолетового $i$ метиленового синього. Встановлено, щчо проиес відповідає моделі Ленгмюра. Позитивні величини ентальпї $i$ негативні величини вільної енергї Гіббса вказують на ендотермічність проиесу. Доведена висока адсорбційна здатність мікрокристалічної изелюлози.

Ключові слова: адсорбент, кристалічний фіолетовий, метиленовий синій, мікрокристалічна целюлоза. 